\title{
ДИДАКТИЧЕСКИЕ АСПЕКТЫ ПОДГОТОВКИ \\ ГЕШТАЛЬТ-ТЕРАПЕВТОВ
}

\author{
Мерсиянова Анжелика Павловна \\ Аспирант \\ Научный руководитель: Кудашов Вячеслав Иванович \\ доктор философских наук, профессор \\ Сибирский Федеральный Университет
}

Аннотация. В статье рассмотрены проблемы стандартизации обучения гештальт-терапии, отражена ситуация подготовки гештальт-терапевтов в постсоветстком пространстве, в том числе дан обзор некоторых методических материалов одного из профессиональных гештальт-сообществ. Выделены основные направления в обучающих процессах, которые возможно и желательно оформить дидактически.

Ключевые слова: гештальт-терапия, обучение гештальт-терапии, дидактика, стандарт образования, формы обучения, эмпирические методы и приемы, теоретическая подготовка, знания, система для самоконтроля.

\section{DIDACTIC ASPECTS OF TRAINING GESTALT THERAPISTS}

\section{Mersiyanova Anzhelika Pavlovna Scientific adviser: Kudashov Vyacheslav Ivanovich}

\begin{abstract}
The article deals with the problems of standardization of gestalt therapy training, reflects the situation of training gestalt therapists in the post-Soviet space, including an overview of some methodological materials of one of the professional gestalt communities. The main directions in the learning processes are highlighted, which are possible and desirable to formalize didactically.

Keywords: gestalt therapy, gestalt therapy training, didactics, standard of education, forms of teaching, experiential methods and techniques, theoretical training, knowledge, a system for self-monitoring.

В конце XX века, когда в педагогике были популярны новые направления, инновации, вопросы индивидуального подхода, будучи 108




\section{НАУКА, ОБЩЕСТВО, ТЕХНОЛОГИИ: ПРОБЛЕМЫ И ПЕРСПЕКТИВЫ ВЗАИМОДЕЙСТВИЯ В СОВРЕМЕННОМ МИРЕ}

студентами психологической специальности, мы регулярно касались данных тем. Запомнилась фраза, озвученная преподавателем: «Педагогика без психологии - это дидактика». К сожалению, сейчас сложно вспомнить, кому принадлежит высказывание. Но для влюбленной в психологию студентки это означало, что дидактика - сухой подход: большая плотность заданий на уроке, практически «дрессировка», обязательно указка и металлический монотонный голос. Педагогический мир разделился на дидактически и психологически ориентированных учителей. Первые вызывали антипатию и осуждение, ну а вторые - были, конечно, «нашими людьми».

При этом глубоких знаний в области дидактики не было, речь шла скорее о субъективном восприятии самого понятия, термина. Долгие годы была уверенность, что внимание к формам, приемам обучения относится к психологическому аспекту педагогической деятельности, нежели дидактическому. Хорошее оснащение дисциплины методическими материалами, структурированность и доступность лекций, разработка заданий для самостоятельной работы студентов трактовались как гуманистические тенденции в педагогике, а не классические принципы и правила организации учебного процесса.

Также нельзя не вспомнить характерное для того периода «нападение» на ЗУНы. Встречался, например, такой оборот, как «пресловутые ЗУНы»: предлагалось отказаться от формирования ЗУН и перейти к развитию компетенций. Действительно, все, что относилось к концепциям ЗУН казалось пережитком. Сейчас отрефлексированный опыт обучения и опыт преподавания в разных системах показывает несостоятельность идеи и вопрос: «Как можно развивать компетенции, перепрыгнув через формирование ЗУН?» кажется очень логичным.

Ценность дидактики была осознана позже, в основном благодаря пониманию самого термина и того, что это понятие наполняется тенденциями времени, но от этого дидактика не перестает быть наукой об обучении.

Последние несколько лет вызывает озабоченность дидактическая часть программ повышения квалификации внутри локального профессионального сообщества психологов, практикующих гештальт-подход. Несмотря на то, что возможность применять принципы классического обучения в гештальтпрограммах вызывает сомнение, а у некоторых даже возмущение, все-таки видится важным выстраивание дидактической системы, учитывающей особенности гештальт-терапии. 


\section{НАУКА, ОБЩЕСТВО, ТЕХНОЛОГИИ: ПРОБЛЕМЫ И ПЕРСПЕКТИВЫ ВЗАИМОДЕЙСТВИЯ В СОВРЕМЕННОМ МИРЕ}

Обучение гештальт-терапии, действительно, имеет свою специфику, так как метод не является набором приемов, он не алгоритмизирован, его невозможно технологизировать и запротоколировать. Это является основной причиной того, что на сегодняшний день метод не утвердил свою валидность через доказательную процедуру (в идеале рандомизированные контролируемые испытания), так как последняя предполагает стандартизацию. Гештальттерапия является одним из наиболее распространенных во всем мире методов, он освещается в справочниках и учебниках по психологии и психотерапии, безусловно признан профессиональным сообществом, но не во многих странах вкючен в клинические протоколы лечения психических расстройств. Однако гештальт-терапия широко применяется психологами частной практики, гештальт-терапевты работают в бюджетных организациях, фондах, коммерческих структурах. Элементы гештальт-терапии активно используют коллеги, работающие в системе страховой психотерапии. Ф.Браунелл в своем руководстве по гештальт-терапии обосновывает альтернативный вариант валидизации метода - «доказательства, основанные на практике», с опорой на многолетний опыт квалифицированных специалистов, экспертов в своей области, которые уверены в действенности терапии без проведения стандартизированных системных исследований, включающих экспериментальные схемы [1, с.15].

Важно сказать также о том, что гештальт-терапия давно вышла за рамки кабинетов индивидуальной и групповой работы. Сегодня она имеет большое прикладное значение, используется в различных сферах (образование, менеджмент, реклама, работа с персоналом). Более того - это социокультурный феномен, «его идеи и принципы уже распространились на различные сферы общества и в определенной степени стали житейским знанием людей» [2, с.263]. В других своих исследованиях мы уже упоминали, что «можно услышать обороты из гештальт-терапевтической лексики в разговорной речи людей, в фильмах, в текстах литературного творчества («незавершенный гештальт», «здесь-и-сейчас» и другие)» [3, с.384]. Это только подтверждает важность и своевременность внесения большей структуры и ясности в методологию обучения гештальт-подходу.

В мире есть несколько больших гештальт-организаций (ассоциаций), которые объединяют под собой множество профессиональных сообществ, реализующих программы обучения в этом направлении. Программы не являются строго регламентированными, позволяя преподавателям быть 


\section{НАУКА, ОБЩЕСТВО, ТЕХНОЛОГИИ: ПРОБЛЕМЫ И ПЕРСПЕКТИВЫ ВЗАИМОДЕЙСТВИЯ В СОВРЕМЕННОМ МИРЕ}

творческими и сохранять свою индивидуальность, что в свою очередь соответствует философским основаниям и методологическим принципам гештальт-подхода. При этом существуют стандарты обучения, очерчивающие общий контур программ и этические правила, положения, включающие основные требования к компетенциям гештальт-терапевтов [4], [5]. Самостоятельно вести эти программы могут специалисты, имеющие большой опыт работы в гештальт-подходе, прошедшие специальную дополнительную подготовку. Программа длительная и сложноструктурированная, предполагает получение слушателями разнообразного по форме и содержанию опыта, завершается процедурой сертификации.

При достаточно большом количестве материалов по гештальт-терапии (индвидуальной и групповой) с акцентами на понимании психологической природы человека, на различных аспектах психотерапевтической деятельности, литературы, посвященной вопросам обучения гештальт-терапевтов недостаточно. Главные требования (стандарты обучения) обязательно есть в каждом гештальт-институте. Со стандартом обучающих программ и профессиональных мероприятий Общества практикующих психологов «Гештальт-подход» можно познакомиться на сайте [6].

Среди доступной литературы, написанной на актуальном для нашей культуры материале, следует выделить пособия по преподаванию И.Д. Булюбаш и И.В. Пугача [7], [8]. Среди публикаций членов нашего профессионального сообщества встречаются статьи, в которых затрагиваются вопросы обучения гештальт-терапевтов, в частности работа Д.Н. Хломова и Н.Б. Долгополова [9], работы Е.Р. Калитеевской [10], Б.А. Дробышевского [11], И.В. Данилова [12], Е.В. Андреевой [13], Е.А. Гончарука [14], А.П. Мерсияновой [15] и др. Имеется несколько опубликованных методических рекомендаций для ведущих и участников учебных программ, которые касаются самого процесса обучения. Важно указать таких авторов, как Н.Б. Кедрова [16], Е.А. Дыхне и Н.И. Голосова [17], Малейчук Г.И. [18]. Автором статьи созданы рабочие тетради, так как данное дидактическое средство очень эффективно при большом объеме самостоятельного обучения [19], [20]. Ежегодно публикуются сборники сертификационных работ выпускников базового курса и третьей (супервизорской) ступени. В целом очевидно, что ведущие учебных программ не часто обобщают свой опыт через написание пособий, методических рекомендаций или статей. 


\section{НАУКА, ОБЩЕСТВО, ТЕХНОЛОГИИ: ПРОБЛЕМЫ И ПЕРСПЕКТИВЫ ВЗАИМОДЕЙСТВИЯ В СОВРЕМЕННОМ МИРЕ}

При этом в сообществе ведется регулярная работа по совершенствованию компетенций гештальт-терапевтов, супервизоров и тренеров. Институты уделяют большое внимание реализации учебных программ и дальнейшего сопровождения коллег: проводятся ежегодные конференции, интенсивы, специализации. В последнее время все чаще открываются специализации именно для преподавателей гештальт-терапии, что в любом случае предполагает постановку задачи усиления методического потенциала сообщества.

Важнейшим принципом гештальт-терапии является опора на опыт. Данный принцип распространяется и на обучение методу. Участники программ на начальных этапах (первый год) погружены в процессы личной и групповой терапии. Они знакомятся с пониманием природы человека в гештальт-подходе и пропускают метод через себя, через собственную клиентскую позицию. Считается также, что благодаря этому на основе импринтинга формируются базовые представления и о самом методе, на которые потом далее накладываются теоретическая информация и практика гештальта. В наших кругах есть слово - «насмотренность», оно отражает основную идею о том, что наблюдение за работой коллег в течении четырех лет и собственная практика в качестве терапевта под супервизией ведущих групп, пребывание в поле гештальт-терапии, участие в динамических гештальт-процессах, позволяет развить необходимые компетенции. Данный механизм формирования компетенций объясняет и концепция «неявного знания» М. Полани. Однако опыт преподавания гештальт-терапии на базовом курсе и в специализациях, участие в интенсивах, работа в качестве супервизора, показали, что имеет место некоторый дефицит классического педагогического подхода.

Теоретическое исследования вопроса дидактики в рамках совершенствования профессиональных качеств специалистов (последипломное образование) осложняется тем, что в самой педагогике данная тема тоже недостаточно раскрыта. Судя по тому, что очень мало литературы, касающейся общих принципов организации повышения квалификации, но встречаются исследования и рекомендации в отдельных областях (повышение квалификации преподавателей высшей школы, учителей и др.), нам тоже придется разрабатывать свою модель.

Данная статья посвящена «примериванию» основных понятий дидактики к процессу обучения гештальт-терапевтов. В своей работе мы опирались на литературу по педагогике и конкретно - дидактике [21], в том числе по 


\section{НАУКА, ОБЩЕСТВО, ТЕХНОЛОГИИ: ПРОБЛЕМЫ И ПЕРСПЕКТИВЫ ВЗАИМОДЕЙСТВИЯ В СОВРЕМЕННОМ МИРЕ}

педагогике и дидактике высшей школы [22], а также на источники по постдипломному образованию [23].

Что полезного можно заимствовать у педагогики, не забывая о специфике метода. Попробуем следом за А.В. Хуторским осмыслить то, как обучать других «собирать коренья». Для этого важно ответить на основные вопросы дидактики:

1. «Для чего, зачем, кого учить?». При обучении взрослых мотивированных людей ответить на этот вопрос значительно легче. Цели обучения в ходе программы постоянно уточняются, становятся более осознанными, конкретизируются.

2. «На какой основе?». Сейчас уже есть четкое понимание, что кроме закономерностей и принципов самого гештальт-подхода важно еще опираться на классические правила обучения.

3. «Чему учить?». Содержание учебных программ определено стандартами институтов, которые в свою очередь руководствуются стандартами профессиональных гештальт-терапевтических организаций, охватывающих целые континенты. Однако здесь тоже есть незаполненные методические ниши, в частности, по очень конкретным вопросам организации гештальт-сессии: «КАК работает гештальт-терапевт», то есть технологические характеристики сессии.

4. «Как учить?». Соответственно, КАК передать слаботехнологизированный метод, с помощью каких приемов, кроме «насмотренности»?

Через какие основные компоненты дидактики можно выстраивается система подготовки гештальт-терапевтов?

Во-первых, конечно, стандарт образования (обязательный и вариативный компоненты), который представлен учебнылм планом и перечнем компетенций, а также системой измерителей результатов образования. Данные стандарты в гештальт-институтах есть: указаны темы, которые необходимо раскрыть, основные формы обучения, количественные требования (количество часов и мероприятий), сертификационные требования (виды сертификационных работ и процедур). Таким образом, задан контур программы, длительность которой в разных институтах колеблется от 3,5 до 4,5 лет.

Во-вторых, важно продолжать разработку системы методов и приемов обучения. В каком-то смысле поле методов и приемов обучения гештальт- 


\section{НАУКА, ОБЩЕСТВО, ТЕХНОЛОГИИ: ПРОБЛЕМЫ И ПЕРСПЕКТИВЫ ВЗАИМОДЕЙСТВИЯ В СОВРЕМЕННОМ МИРЕ}

подходу определено спецификой самого подхода. Мы можем говорить о том, что доминирующим типом (методической системой) обучения является эмпирический (экспериенцальным , «опытный», практический) тип, когда даже теоретический материал важно давать после «проживания» участниками групп определенного опыта. Формы организации учебного процесса на базовом курсе достаточно разнообразные, что позволяет формировать и закреплять навыки гештальт-терапии в различных условиях, а также, что существенно в данном направлении, - формировать личность гештальт-терапевта. К основным формам в гештальт-обучении относят: учебные модули, практикум (самостоятельная работа в малых группах) «полевой» практикум (реальный опыт в роли гештальт-терапевта), личная индивидуальная терапия, групповая терапия, индивидуальная и групповая супервизия, интенсивы, практические конференции, специализации, мастер-классы, семинары, лекции.

И.Д. Булюбаш и Н.В. Пугач большое внимание уделяют особенностям формирования умений и навыков гештальт-терапевтов, указывая на то, что соотношение между дидактическим и экспериенцальным (упражнения, эксперименты, супервизия) должно быть в пользу последнего. Здесь под дидактическим компонентом скорее всего понимается линия передачи знаний через классические педагогические приемы (лекция, чтение литературы), хотя выше уже указывалось, что дидактика включает в себя разные методы, в том числе и эмпирические (экспериенцальные). Авторы пишут, что «выраженный дидактический стиль у группы в целом и у участников программы может свидетельствовать о застревании группового и индивидуального развития на стадии интроекции, что требует существенного изменения стратегии преподавания в данной группе» [7, c.133]. Разделяя точку зрения о важности доминирования эмпирического типа обучения, все же хочется отметить, что определенная нехватка теоретических знаний, позволяющих участникам программ лучше осознавать и дифференцировать терапевтический процесс, все же имеет место.

Нужны ли гештальт-терапевту «знания», когда важнейшей компетенцией является «чувствительность»? Достаточно ли просто интериоризированных (через «насмотренность») умений и навыков, без глубокого осмысления, которые все же предполагают владение понятийным аппаратом и словеснологическое оформление? Многолетний опыт показывает, что теоретическая подготовка участников базового курса (первая и вторая ступень) - важная 


\section{НАУКА, ОБЩЕСТВО, ТЕХНОЛОГИИ: ПРОБЛЕМЫ И ПЕРСПЕКТИВЫ ВЗАИМОДЕЙСТВИЯ В СОВРЕМЕННОМ МИРЕ}

составляющая программы, которая обеспечивается через специфические дидактические средства.

В связи с тем, что на сегодняшний день теоретическая подготовка участников гештальт-программы является недостаточной, остановимся немного на данном аспекте.

Согласно педагогическим словарям, знание в широком смысле слова это проверенный практикой результат познания действительности, верное ее отражение в мышлении человека. Знание выступает в виде понятий, законов, принципов, суждений. Оно может быть выведено из опыта (эмпирическое знание), и может быть усвоенным через сохранение в памяти и воспроизведение фактов науки, понятий, правил, законов, теорий. Теоретическое знание отражает закономерные связи и отношения; направлено на объяснение объективной реальности, описание, систематизацию и объяснение множества данных эмпирического уровня, идеальных объектов, знание о сущности, т.е. отношении, которое составляет основание отдельных отношений [24].

Как указывают в своей статье, посвященной теоретическому обоснованию критериев и показателей сформированности компетентностей обучающихся, Т.Е. Наливайко и М.В. Шинкорук: «систему качеств знаний образуют: полнота, глубина, конкретность, обобщенность, свернутость, развернутость, системность, систематичность, осознанность, гибкость, оперативность, прочность знаний» [25, с.25].

Надо сказать, что в гештальт-сообществах по-разному относятся к теоретической подготовке: где-то она полностью отдана в ответственность студентов, а какие-то институты организуют обязательные лекционные курсы и осуществляют контроль за качеством знаний через экзаменацию.

В нашем сообществе акцент на формировании знаний участников программ не ставится, приоритет отдается развитию чувствительности, наработке опыта, формированию «неявного знания», развитию компетенций в организации контакта, решении отношенческих проблем. Не умаляя важности перечисленного, хочется повысить теоретический уровень подготовки выпускников наших программ, но не через добавление часов или изменения пропорции между эмпирическими и теоретическими компонентами, а через разработку учебно-методической базы для самостоятельного теоретического продвижения участников. 


\section{НАУКА, ОБЩЕСТВО, ТЕХНОЛОГИИ: ПРОБЛЕМЫ И ПЕРСПЕКТИВЫ ВЗАИМОДЕЙСТВИЯ В СОВРЕМЕННОМ МИРЕ}

Издание книг, публикация статей на тему гештальт-терапии, а также ее интеграции с другими методами сегодня стало уже привычным делом для профессиональных сообществ постсоветсткого пространства (Д.Н. Хломов, Н.Б. Кедрова, А.Н. Моховиков, Е.В. Медреш, Г.И. Малейчук, Л.Л. Третьяк, О.В. Немиринский, Н.Б. Долгополов, И.А. Погодин, И.Д. Булюбаш, Н.М. Лебедева, Е.А. Иванова и др.). Данная литература рекомендуется к прочтению наряду с классическими источниками, написанными основателями гештальт-подхода (Ф.Перлз, Л.Перлз, Дж.Зинкер, П.Гудмен и др.), а также современными зарубежными методологами (Г. Уилер, Ж.-М. Робин, П. Филиппсон и др.). Однако, как уже отмечалось - есть серьезный дефицит именно в учебно-методическом сопровождении учебного процесса.

С целью усиления дидактической части гештальт-программ важно создать единую базу, где будет собран весь материал, имеющийся в открытом доступе, а также ссылки на книги, которые возможно будет приобретать на специализированных сайтах. Таким образом, участники смогут при необходимости найти нужную книгу (статью) в каталоге, сохранить себе или приобрести.

Кроме этого необходимы учебно-методических материалы (пособия, рекомендации, рабочие тетради, сборники схем и таблиц) для преподавателей и участников программ по гештальт-терапии и гештальт-супервизии.

Спорным вопросом в обучение гештальт-подходу является ситуация контроля и оценивания. Безоценочное отношение, заложенное в гештальтподходе важно распространять и на сам учебный процесс, иначе как участники программ пропитаются данной философией. Есть отдельный вид - «оценочная супервизия», ее используют некоторые гештальт-институты перед процедурой сертификации, чтобы участник мог понять, в каком направлении ему развивать свои компетенции. Так или иначе контроль и оценка в широком смысле этих слов, конечно, имеют место. Ведущие учебных или супервизорских групп осуществляют корректирующее и направляющее воздействие на работу участников в качестве терапевтов, но задача делать это не в категориях «правильно/неправильно». Конечно, в случае полного несоответствия терапевтической работы участника стандартам гештальт-терапии руководитель программы не рекомендует его к сертификации.

Гештальт-институты на свое усмотрение могут включать в стандарт тестирование теоретических знаний. Возможно когда-нибудь это станет 


\section{НАУКА, ОБЩЕСТВО, ТЕХНОЛОГИИ: ПРОБЛЕМЫ И ПЕРСПЕКТИВЫ ВЗАИМОДЕЙСТВИЯ В СОВРЕМЕННОМ МИРЕ}

обязательным для всех, кто планирует быть сертифицированным гештальттерапевтом.

Негативное отношение к контролю знаний в нашем обществе связано с тем, что он часто используется, как средство отсева, фильтра. Оценивание идет по уровням, педагогическая диагностика завершается отметкой, которая так или иначе лежит в плоскости понятий «правильно/неправильно», что для нашей ментальности означает «хорошо/плохо». Это не означает, что контроль знаний не нужен, но в рамках обучения гештальт-терапии важно сначала сформировать у участников иное восприятие контроля знаний и оценки (в широком смысле слова). И, конечно, ведущим групп важно быть уверенными, что с их стороны программа была методически оснащена и в таком случае возможна унифицированная проверка знаний.

Рассматривая задачу учебно-методического обеспечения программ нашего профессионального сообщества, считаю очень полезным формирование системы заданий для самопроверки. В качестве способа диагностики знаний можно использовать классические тесты (утверждение или вопрос с вариантами ответов, либо с открытым ответом), а также психотерапевтические кейсы, которые не предполагают правильного ответа, но позволяют участнику программы сопоставить свое решение с некоторым количеством вариантов. Текущий самоконтроль, самопроверка с помощью тестирования позволит участникам видеть свои зоны роста в плане теоретической подготовки. Кроме этого в тестах, несмотря на их ограниченность, заложена способность помочь учащемуся дифференцировать информацию о предмете изучения. То есть тесты - это не только контроль и самоконтроль, это также хороший инструмент формирования знаний, что является сильнейшим аргументом важности включения их в учебный процесс.

Таким образом, анализ программ обучения гештальт-терапии показал, что вектором их развития является учебно-методическое обеспечение. Много литературы (в том числе написанной гештальт-терапевтами нашего пространства), посвящено непосредственно представлениям гештальт-подхода о природе человека, психической норме и патологии, о межличностных отношениях. Уделяется внимание и самому процессу гештальт-терапии: описываются стадии процесса, то, что происходит с терапевтом и клиентом, инструменты гештальт-подхода дифференцируются от приемов других направлений. На фоне такого разнообразия обнаруживается дефицит учебнометодического материала для ведущих обучающих программ. Участники 


\section{НАУКА, ОБЩЕСТВО, ТЕХНОЛОГИИ: ПРОБЛЕМЫ И ПЕРСПЕКТИВЫ ВЗАИМОДЕЙСТВИЯ В СОВРЕМЕННОМ МИРЕ}

программы также опираются на монографии и статьи, что с одной стороны, конечно, логично при обучении взрослых, но с другой - сопровождение учебного процесса дидактическими средствами (рабочие тетради, сборники схем и таблиц, тесты для проверки знаний) - важное условие эффективности обучения, качества знаний и уровня сформированности компетенций.

\section{Список литературы}

1. Brownell P. Gestalt therapy: a guide to contemporary practice. - Springer Publishing Company. - 2010 - 288 p.

2. Мерсиянова А.П. От гештальт-терапии к гештальт-подходу: образование, менеджмент, культура, жизненная философия // Наука и образование в контексте глобальной трансформации: сборник статей II Международной научно-практической конференции (24 января 2022 г.). Петрозаводск : МЦНП «Новая наука», 2022. - с.259-265.

3. Кудашов В.И., Мерсиянова А.П. Гештальт-подход как социокультурный феномен // Материалы Всероссийской научно-практической конференции «Трансформация информационно-коммуникативной среды общества в условиях вызовов современности» с международным участием Комсомольск-на-Амуре, 25-26 ноября 2021 года. - С.384-387.

4. Видакович И., Злесков-Дьорич Е., Рубал Я. и др. Профессиональные компетенции и стандарты качества: специфические компетенции гештальттерапевтов / / под ред. Р. Поповой. - Казань: Центр инновационных технологий, 2014. $-56 \mathrm{c}$.

5. Сонькин В. Образовательный стандарт обучения гештальт-терапии (предисловие к русскому переводу). - М.: Объединение «Метаморфозы». -

https://metamorphosis.ru/wp-content/uploads/2020/09/standart-obucheniyageshtalt-terapii.pdf (дата обращения 09.02.2022)

6. Структура подготовки в МГИ // Сайт Общества практикующих психологов «Гештальт-подход». - https:/gestalt.ru/programma/ (дата обращения 13.02.2022)

7. Булюбаш И.Д., Пугач И.В. Руководство по обучению гештальттерапевтов. - Самара: Издательский Дом «Бахрар-М», 2019. - 416 с.

8. Булюбаш И.Д., Пугач И.В. Теория и практика групповой гештальттерапии. - Самара: Издательский Дом «Бахрар-М», 2020. - 304 с. 
9. Хломов Д.Н., Долгополов Н.Б. Фигура гештальта в России // Московский психотерапевтический журнал. - 1994. - №3.

10. Калитеевская Е.Р. Формирование личности гештальт-терапевта // Гештальт-терапия. Размышления. Статьи. - М.: Постатор, 2021. - 209 с. (С.8795)

11. Дробышевский Б.А. Методические заметки о супервизии «троек» // Сборник Московского гештальт-института за 2011 / Под ред.Д. Хломова. - М.: ОППГП, 2011. - 188 с. (С.10-112)

12. Данилов И.В. Размышление на тему преподавания гештальт-терапии и супервизии участников обучающих программ // Сборник Московского гештальт-института за 1999 / Под ред.Д. Хломова. - М.: МГИ, 2000. - 83 с. (C.65-68)

13. Андреева Е.В. От практики к теории и наоборот // XX Конференция «Московский гештальт-институт» / Под ред.Д. Хломова. М.: ОППГП, 2011. 188 c. (C. 124-132.)

14. Гончарук Е.А. Как провести феноменологическое исследование в гештальт-подходе // Личная философия психотерапевта: сборник материалов Московского гештальт-института. - М.: ОППГП, 2009. - с.110 (С.17-19)

15. Мерсиянова А.П. «Супервизора вызывали?» или о супервизии малых групп в обучающих программах // Сборник материалов Общества практикующих психологов "Гештальт-подход" (Зимняя школа - 2021). - М.: ОППГП, 2021. - С.100-106.

16. Кедрова Н.Б. Восстановление контакта с детьми. Материалы к специализации. - М.: ОППГП, 2021. -55 с.

17. Дыхне Е.А., Голосова Н.И. Групповая психотерапия. Методические материалы КТЦ Гештальт-анализа. - М.: МГИ, 2008. - 54 с.

18. Малейчук Г.И. Принципы организации психотерапевтических экспериментов // Парадоксы симптома. Системно-аналитический подход в работе с психосоматическим симптомом. - М.: Академический Проект, 2020. C.210-212.

19. Мерсиянова А.П. Рабочая тетрадь по книге «Эго, голод и агрессия» Ф. Перлза. - https://www.b17.ru/book/knigaegort/ (дата обращения 13.02.2022)

20. Мерсиянова А.П. Рабочая тетрадь для занятий СРСП и СРС по дисциплине «Основы гештальттерапии». - Усть-Каменогорск: Издательство КАCУ, 2007. - 32 c. 
21. Загвязинский В.И., Емельянова И.Н. Общая педагогика. - М.: Высш. шк., 2007. - 394 c.

22. Макарова Н.С., Дука Н.А., Чекалева Н.В. Дидактика высшей школы. От классических оснований к постнеклассическим перспективам. - М.: Издательство Юрайт, 2019. - 172 с.

23. Мицкевич Н.И. Теоретические основы дидактической системы повышения квалификации : автореферат дис. ... доктора педагогических наук : 13.00.08 / Ин-т образования взрослых Рос. акад. образования. - СанктПетербург, 2001. - 50 с.

24. Профессионально-педагогические понятия: Словарь / Под ред. Г. М. Романцева. - Екатеринбург: Изд-во РГГПУ, 2005. - 456 с.

25. Наливайко Т.Е., Шинкорук М.В. Теоретическое обоснование критериев и показателей сформированности компетенций обучаемых// Ученые записки Комсомольского-на-Амуре государственного технического университета. - 2013. - №1(13). - С.23-30. 